\title{
Exploring the Origins of Charitable Acts: Evidence from an Artefactual Field Experiment with Young Children
}

\author{
John A. List ${ }^{\mathrm{a}}$ and Anya C. Samak ${ }^{\mathrm{b}}$ \\ ${ }^{a}$ University of Chicago and National Bureau of Economic Research \\ 1126 East $59^{\text {th }}$ Street, Chicago, IL 60637, USA \\ ${ }^{\mathrm{b}}$ University of Wisconsin-Madison \\ 1300 Linden Drive, Madison, WI 53706, USA
}

August 22, 2012

\begin{abstract}
An active area of research within economics concerns the underpinnings of why people give to charitable causes. This study takes a new approach to this question by exploring motivations for giving among children aged 3-5. Using data gathered from 122 children, our artefactual field experiment naturally permits us to disentangle pure altruism and warm glow motivators for giving. We find evidence for the existence of pure altruism but not warm glow. Our results suggest pure altruism is a fundamental component of our preferences, and highlight that warm glow preferences found amongst adults likely develop over time. One speculative hypothesis is that warm glow preferences are learned through socialization.
\end{abstract}

JEL Classifications: C93, D03, D64

Keywords: altruism, warm glow, preference development

Corresponding author: Anya Samak, Email: asamak@wisc.edu Phone: 1-608-262-5498 


\section{Introduction}

Charitable giving has grown in importance in the Western World, where in some economies gifts of money now exceed 2\% of GDP (List and Peysakhovich, 2011). Even though stakes are high, until the past several years even the most primitive facts concerning why people give remained unknown. Recently, a series of natural field experiments have lent insights into the "demand side" of charitable fundraising. The data generated test existing theories and provide crucial behavioral parameters that help to construct new theories. Empirical insights are important for fundraisers, policymakers, and academics alike.

As a whole, experimental, neural, and hormonal studies suggest that the propensity to give is an evolutionary trait, with even young children displaying other-regarding behavior (Benenson et al., 2007; Harbaugh et al., 2003; Kosfeld et al., 2005). Two factors-warm glow and altruism - have been found to be important determinants of giving (Crumpler and Grossman, 2008; Goeree et al., 2002). We take the economics literature in a new direction by disentangling the foundation of pure altruism and warm glow motivators for giving among children ages 3-5 (Andreoni, 1989, 1990). Conducting an artefactual field experiment (see the field experimental definitions in Harrison and List, 2004) with 122 children, we find evidence in favor of pure altruism, but not warm glow among our young subjects. These data open up the possibility that there is a fundamental nature of pure altruism, and that the warm glow preference observed in adults might develop over time, and is learned via socialization.

\section{Experimental Design}

We designed dictator games in which children were matched with anonymous students or 'teddy bears'. In each round, children received 5 marshmallows and decided how many to keep 
and how many to send to their match. Each of the 4 possible matches were represented by a photo of the match's hand/paw, and was referred to as 'a child [teddy] in another room, let's call the child [teddy] Pat/Tap [... who] didn't get to play this game today' (see Figure 1). Student matches received the designated marshmallows after the experiment was completed. ${ }^{1}$

The design is based on the fact that purely altruistic individuals receive utility solely from increasing welfare of others, while individuals motivated by 'warm glow' receive utility from the act of giving itself (Andreoni, 1989, 1990). The premise of our approach was an environment in which sending a marshmallow to the match results in an increase of utility for the match, and a different environment in which sending a marshmallow to the match does not result in an increase of utility for the match (thereby isolating pure altruism). This is similar in spirit to lab experiments that 'burn' dollars to isolate warm glow (Crumpler and Grossman, 2008).

The following details of the experiment were explained to children: (1) While children eat marshmallows, they cannot eat cotton balls; therefore, cotton balls have no value to children. (2) Teddy bears cannot eat marshmallows and marshmallows have no value to teddy bears, but teddy bears like cotton balls. (3) Each marshmallow sent by the child to the match is passed through a box and placed in the bag for the match. In some sequences, this is a 'regular box,' and marshmallows are sent through with no change. In other sequences, this is a 'magic box,' and marshmallows that are sent through are 'magically' converted into cotton balls. While suspending disbelief this way may be unnatural for an adult, experiments with children in psychology often use puppets with human-like preferences (e.g., Olson and Spelke, 2008).

Treatments are summarized in Table 1. Student-Magic (SM) and Teddy-Regular (TR) isolate warm glow from altruism, since sending a student a cotton ball or a teddy bear a marshmallow provides no value to the match. Treatments Student-Regular (SR) and Teddy-

\footnotetext{
${ }^{1}$ There was no Teddy Bear match, however.
} 
Magic (TM) include both warm glow and altruism - sending a student a marshmallow or a teddy bear a cotton ball provides value. Two baselines isolate any positive utility from sending marshmallows through a box - in Baseline-Magic (BM) and Baseline-Regular (BR), items sent through the box go into trash. Each child participated in a series of either student or 'teddy' match games. Each set included one baseline, 2 warm glow (SM or TR) and 2 warm glow and altruism (SR or TM) treatments (see Table 2).

The studies were conducted at the Griffin Early Childhood Center in 2010. Children were told that they would 'play a game' one-on-one with the experimenter and that there would be marshmallows. Further details of the procedures and instructions can be found in Appendix A.

\section{Results}

122 preschool children participated in the study, with 71 participants in the Student matching and 51 in the Teddy matching. On average, children gave 1.27 marshmallows, or $25.4 \%$ of their endowment to the match. This is similar to donations in a related study on 4-year olds' giving (Benenson et al., 2007). Children display heterogeneity in giving, ranging from selfish to other-regarding, in line with studies of adults (Cooper and Kagel, 2009). 91 participants gave at least 1 marshmallow in at least 1 sequence, while 41 participants gave 0 marshmallows in all sequences, see Figure 2. Our results confirm that other-regarding preferences are alive and well at this young age, at least for $69 \%$ of children in our study:

Result 1: Children as young as 3-5 years old do have other-regarding preferences, giving on average $25.4 \%$ of their endowment to their match.

Our design allows us to isolate purely altruistic giving from warm glow giving. Table 1 summarizes the average amount of marshmallows sent by treatment. We provide the raw results 
and the 'magic-box' adjusted results, which adjust the average by the difference between the two baselines. $^{2}$ The adjustment is needed because of the added utility from sending items through the magic box. On average, participants matched with students give $22 \%$ in SM and $31 \%$ in SR, suggesting that pure altruism makes up $9 \%$ of the difference. Participants matched with teddies give $18 \%$ in TR and $30 \%$ in TM, suggesting that pure altruism makes up $12 \%$ of the difference. However, difference between baseline and 'warm glow' treatments is $-9 \%$, suggesting that the 'warm glow' motivation is not strong in children of this age.

We conducted Wilcoxon signed-rank tests for matched pairs, averaging giving to 'Tap'/‘Pat' for each child and adjusting for the effect of 'magic box.' We find that giving is significantly greater in treatments with 'warm glow and altruism' compared to treatments with 'warm glow' only ( $p$-value $=0.00$ ). We find significant differences between SR as compared to SM ( $p$-value $=0.02)$. However, we do not find that giving is significantly different in TM versus TR $(p$-value $=0.39)$, except for when using unadjusted rates $(p$-value $=0.00)$. This may not mean that pure altruism is less likely, but could indicate that children believe teddy bears get less utility than children from the gift. We also compared giving in baseline to giving in 'warm glow' treatments, and cannot reject that these are equal ( $p$-value $=0.43)$. Additional random-effects panel analyses with controls (available in Appendix B) support these results.

Result 2: When warm glow is ruled out, pure altruism is a significant motivator for giving among young children.

Previous literature has found that girls are more pro-social than boys (Eisenberg et al., 1998). Our data supports this finding - aggregating games with altruism, girls gave an average of 1.91 marshmallows while boys gave an average of 1.09 , a statistically significant difference that is not due to differences at baseline ( $p$-value $=0.01)$.

\footnotetext{
${ }^{2}$ The remainder of the analysis will proceed using the adjusted scores.
} 
Result 3: Girls are more altruistic than boys at this age.

\section{Conclusion}

One fact that has emerged across the globe is that people help others. Economists still lack a deep understanding of the underpinning of such actions - is it altruism or something purely self-interested, such as warm glow? We help answer these questions by conducting an experiment aimed at disentangling warm glow and pure altruism motivators for giving among young children. We find evidence for the existence of pure altruism but not warm glow. Future work should build on these results by uncovering the path to which warm glow emerges in humans. In particular, if children 'learned' altruism or warm glow through socialization, we may expect choices to be correlated with SES (they are not with our young subject pool). By conducting such studies, we can better model why people give, deepen our understanding of the sources of giving, and design mechanisms to promote the efficient level of public good provision. 


\section{References}

Andreoni, J. (1989). Giving with impure altruism: Applications to charity and Ricardian equivalence. Journal of Political Economy, 97(6), 1447-1458.

Andreoni, J. (1990). Impure altruism and donations to public goods: A theory of warm-glow giving. The Economic Journal, 100(401), 464-477.

Benenson, J. F., Pascoe, J., \& Radmore, N. (2007). Children's altruistic behavior in the dictator game. Evolution and Human Behavior, 28(3), 168-175.

Cooper, D., and Kagel, J. (2009) "Other Regarding Preferences: A Selective Survey of Experimental Results," Handbook of Experimental Economics, 2 (2009).

Crumpler, H. \& Grossman, P.J. (2008). An experimental test of warm glow giving. Journal of Public Economics, 92(5-6), 1011-1021.

Eisenberg, N., Fabes, R. A., \& Spinrad, T. L. (1998). Prosocial development. In N. Eisenberg, W. Damon \& R. Lerner (Eds.), Handbook of child psychology: Social, emotional, and

Goeree, J. K., Holt, C. A., Laury, S. K. (2002). Private costs and public benefits: unraveling the effects of altruism and noisy behavior. Journal of Public Economics, 83(2), 255-276.

Harbaugh , W. T., Krause, K., \& Liday , S. J. (2003). Bargaining by children. Unpublished manuscript, Department of Economics, University of Oregon.

Harrison, G.W. and List, J.A. (2004). Field Experiments. Journal of Economic Literature, 42 (4), 1009-1055.

Kosfeld, M., Heinrichs, M., Zak, P., Fischbacher, U., \& Fehr, E. (2005). Oxytocin increases trust in humans. Nature, 435(1042), 673-676.

List, John A. and Yana Peysakhovich, "Charitable Donations are More Responsive to tock Market Booms than Busts,” Economics Letters, (2011), 110 (2): pp. 166-169. 
Olson, K. R., \& Spelke, E. S. (2008). Foundations of cooperation in young children. Cognition, $108(1), 222-231$. 
Figure 1: Matches

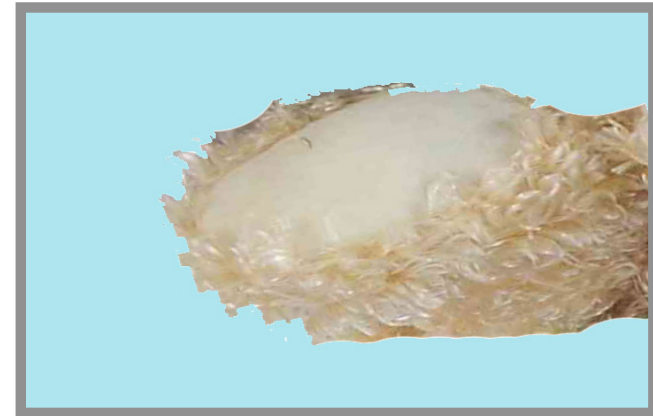

"Pat the Teddy Bear's" Paw

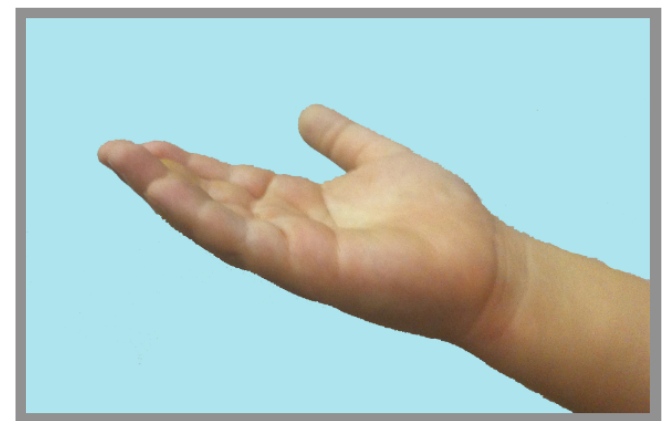

"Pat the Child's" Hand

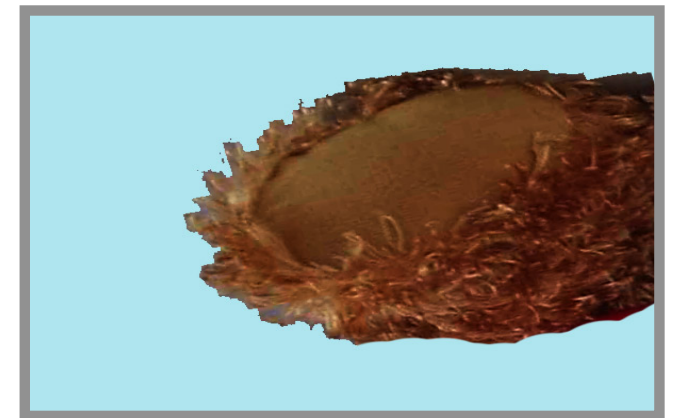

“Tap the Teddy Bear's” Paw

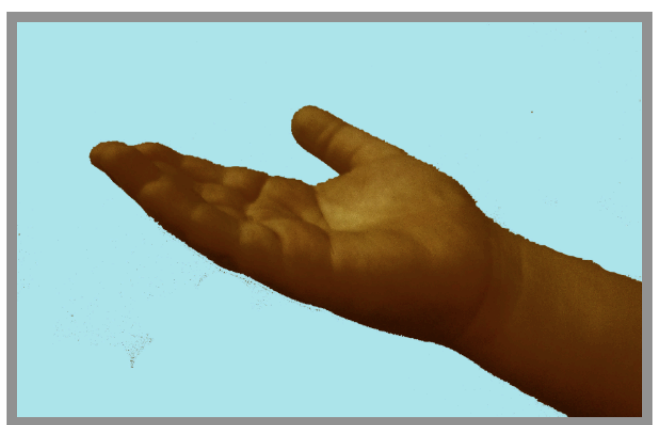

“Tap the Child's" Hand

Figure 2: Histogram of Choices (Baseline Excluded)

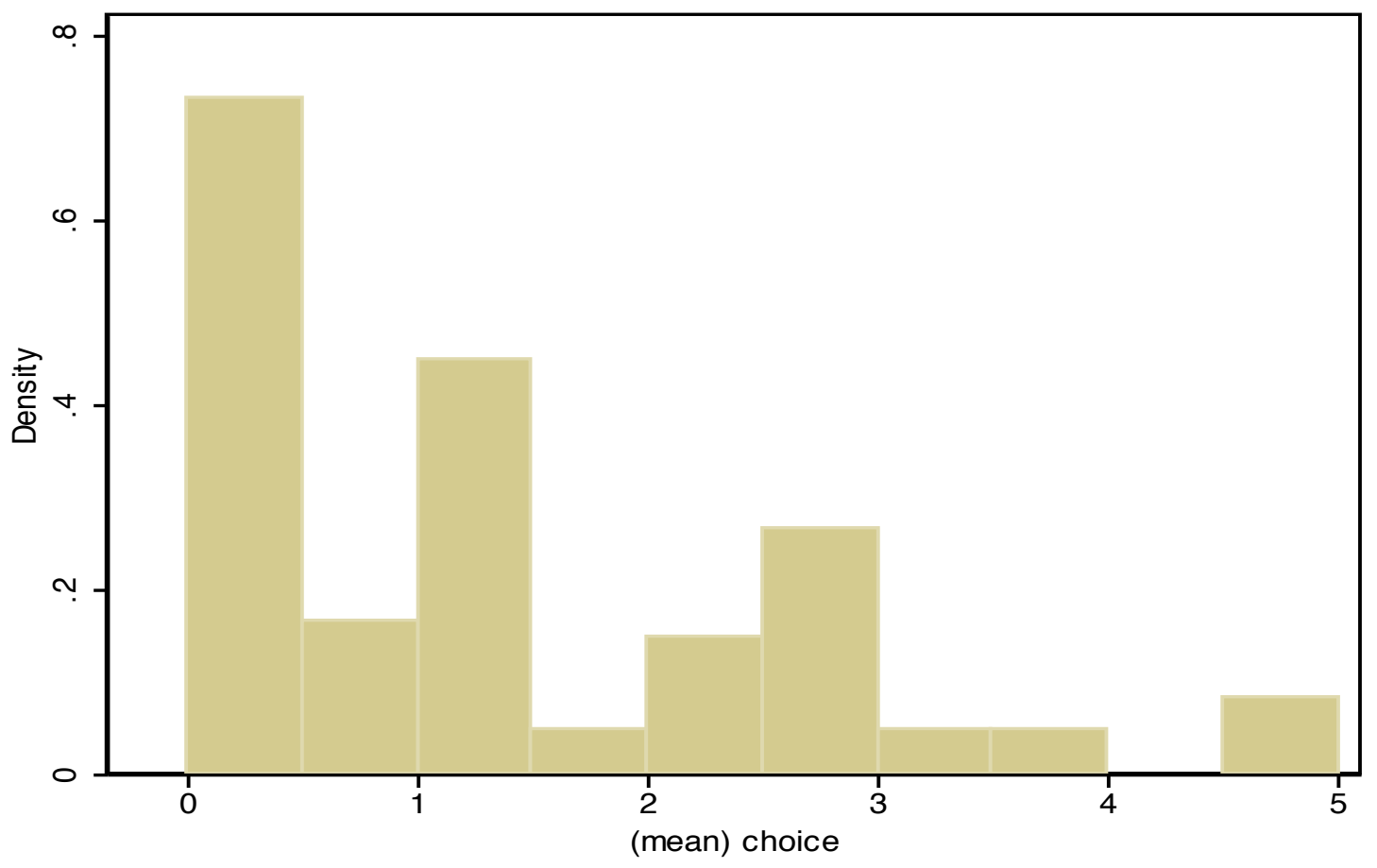


Table 1: Summary of Treatments and Results

\begin{tabular}{|l|l|l|l|}
\hline & Matched with Student & Matched with Teddy & No Match (Trash) \\
\hline Magic Box & SM - Warm Glow & TM - Warm Glow + Altruism & BM - Baseline (Magic) \\
& Raw: 1.09 or 22\% (1.47) & Adju or 35\% (1.65) & 1.55 or 31\% (2.08) \\
& & Adjusted: 1.52 or 30\% (1.65) & \\
\hline $\begin{array}{l}\text { Regular } \\
\text { Box }\end{array}$ & SR - Warm Glow + Altruism & TR - Warm Glow & BR - Baseline (Regular) \\
& Raw: 1.32 or 26\% (1.58) & 0.91 or $18 \%(1.45)$ & 1.33 or 27\% (1.96) \\
& Adjusted: 1.54 or 31\% (1.58) & & \\
\hline
\end{tabular}

*Adjusted values add the average difference between sending choices in the Baseline Regular (BR) and Baseline Magic (BM) treatments, which was 0.22. Standard deviations in parantheses.

\section{Table 2: Participant Assignment}

\begin{tabular}{|c|c|c|c|}
\hline \multicolumn{2}{|c|}{ Matched with Students (Pat and Tap) } & \multicolumn{2}{|c|}{ Matched with Teddy Bears (Pat and Tap) } \\
\hline Sequence of Treatments & \# of students & Sequence of treatments & \# of students \\
\hline 1. $\mathrm{BR}-\mathrm{SR} * 2-\mathrm{SM} * 2$ & $9(9)$ & 9. $\mathrm{BR}-\mathrm{TR} * 2-\mathrm{TM} * 2$ & $7(7)$ \\
\hline 2. $\mathrm{SR} * 2-\mathrm{SM}^{*} 2-\mathrm{BR}$ & $7(8)$ & 10. $\mathrm{TR} * 2-\mathrm{TM} * 2-\mathrm{BR}$ & $7(7)$ \\
\hline 3. $\mathrm{BM}-\mathrm{SR} * 2-\mathrm{SM} * 2$ & $9(10)$ & 11. $\mathrm{BM}-\mathrm{TR} * 2-\mathrm{TM} * 2$ & $4(5)$ \\
\hline 4. $\mathrm{SR} * 2-\mathrm{SM} * 2-\mathrm{BM}$ & $9(10)$ & 12. $\mathrm{TR} * 2-\mathrm{TM} * 2-\mathrm{BM}$ & $8(8)$ \\
\hline 5. $\mathrm{BR}-\mathrm{SM} * 2-\mathrm{SR} * 2$ & $10(11)$ & 13. $\mathrm{BR}-\mathrm{TM} * 2-\mathrm{TR}^{*} 2$ & $5(7)$ \\
\hline 6. $\mathrm{SM}^{*} 2-\mathrm{SR} * 2--\mathrm{BR}$ & $8(8)$ & 14. $\mathrm{TM} * 2-\mathrm{TR} * 2--\mathrm{BR}$ & $6(6)$ \\
\hline 7. $\mathrm{BM}-\mathrm{SM} * 2-\mathrm{SR} * 2$ & $9(11)$ & 15. $\mathrm{BM}-\mathrm{TM}^{*} 2-\mathrm{TR} * 2$ & $7(8)$ \\
\hline 8. $\mathrm{SM}^{* 2}-\mathrm{SR}^{* 2}-\mathrm{BM}$ & $10(10)$ & 16. $\mathrm{TM} * 2-\mathrm{TR} * 2-\mathrm{BM}$ & $7(7)$ \\
\hline Total & $71(77)$ & 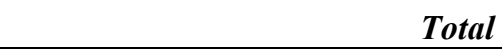 & $51(55)$ \\
\hline
\end{tabular}

\section{Acknowledgements}

We thank the Griffin Foundation for funding. We thank Edie Dobrez and Phuong Ta for research assistance and seminar participants at Chapman University for comments. 